\title{
Impact of Vegetation Cover Structure on Birds' Community at Tianfu National Wetland Park in Jiangsu Kunshan, China
}

Fathielrahaman. H. Ajloon ( $\nabla$ ajloon666@yahoo.com )

Nanjing Forestry University

Dong Xie

Nanjing Forestry University

Shao Junxue

Nanjing Forestry University

Zhang RuiTing

Nanjing Forestry University

Aniefiok Ini Inayng

Chinese Academy of Sciences

\section{Research Article}

Keywords: Avian diversity, plant assemblage, species interaction, wetlands ecosystem

Posted Date: September 27th, 2021

DOI: https://doi.org/10.21203/rs.3.rs-893247/v2

License: (c) (1) This work is licensed under a Creative Commons Attribution 4.0 International License. Read Full License 


\section{Impact of Vegetation Cover Structure on Birds' Community at Tianfu}

\section{National Wetland Park in Jiangsu Kunshan, China}

Fathielrahaman.H.Ajloon ${ }^{1 *}$, Dong Xie ${ }^{1.2}$, Shao. Junxue ${ }^{1,}$ Zhang. RuiTing ${ }^{1}$, Aniefiok Ini Inayng ${ }^{3,4}$

1. Department of Ecology, College of Biology and the Environment, Nanjing Forestry University, Nanjing, China.

2. Co-Innovation Center for Sustainable Forestry in Southern China, Nanjing Forestry University, Nanjing 210037, China

3. State Key Laboratory of Tropical Oceanography, South China Sea Institute of Oceanology, Chinese Academy of Sciences, Guangzhou 510301, China

4. Department of Marine Biology, Akwa Ibom State University, Ikot Akpaden,

\section{Nigeria}

Corresponding author: ajloon666@yahoo.com.

Contributing author: xiedong0123@gmail.com

Contributing author: aniefiokinyang@yahoo.com 


\begin{abstract}
Vegetation cover has an essential role in wetland habitats in controlling avian populations throughout the world. The vegetation cover structure in grassland systems varies dramatically among seasons on the same sites. Variation in vegetation cover-abundance richness and diversity has been studied through one hundred forty-seven quadrate samples during summer and autumn, 2019, winter, and spring 2020. Avian species richness and diversity were recorded during the same period. Meanwhile, correlation analysis results confirmed that: (1) there was no apparent seasonal difference in the abundance of vegetation cover while avian abundance was statistically different. (2) Plant abundance in summer was positively correlated with the number of avian, while in autumn it was negatively correlated. Plant and avian abundance at the genus level showed a positive correlation while maintaining a negative correlation at the species level $(p<0.05)$. However, during summer and autumn, a strong linear relationship exists between vegetation coverage and avian. The Shannon diversity index and Simpson diversity index have a positive linear relationship between vegetation coverage and avian families and genera. Therefore, we conclude that vegetation coverage and richness significantly impact avian communities. We suggest further research into the relationship between other biological communities and farming practices in the wetlands.
\end{abstract}

Keywords: Avian diversity, plant assemblage, species interaction, wetlands ecosystem. 


\section{Introduction}

Vegetation creates opportunities for reproduction and identifies ideal living conditions for avian communities. Therefore, the diversity of vegetation determines the species richness, while good quality habitats can provide suitable forage places and nesting opportunities, thus ensuring the longevity of a species. Another primary indicator of the relationship between avian community and vegetation is avian diversity. Avian diversity was a good predictor of tree density [1], which means species occurrences declined as resource availability decrease, and breeding sites reduced relative to the percentage of vegetation cover remaining [2]. Simultaneously, avian community structure and composition can also be affected by local environmental factors such as predation and competition, and by large-scale ecological factors, such as the structure and the degree of habitat isolation ${ }^{[3-5]}$.

Vegetation is the central part of the terrestrial ecosystem and is considered a sensitive indicator for environmental change as it reflects the land cover change to a certain extent ${ }^{[6,7]}$. Wetlands are essential for many wildlife forms as they appreciated providing quality and abundant habitats concerning avian communities and vegetation composition [8]. The vegetation structure and composition often strongly influence avian distribution ${ }^{[9,10]}$. Besides, avian is commonly monitored to assess the biological consequences of management interventions and disturbance regime changes ${ }^{[11,12]}$. Avian and vegetation depend not only on each other but also on the entire food chain for additional food, shelter, and reproduction.

All in all, the species traits provide a mechanistic link between the functional diversity of the avian community and the landscape characteristics, for they are directly related to vegetation characteristics ${ }^{[13]}$. The increased concerns of climate change have prompted research in preserving our wildlife, more notably wetlands. Wetlands are threatened ecosystems ${ }^{[14,15]}$ that inhabit many wildlife species and are the core haven for their survival. Climate change imposes extinction on this way of life. However, it can be noted that human population growth coupled with the rise in demand for settlements, agricultural land, and wood products is altering essential wildlife habitats, avian diversity patterns, and overall biodiversity worldwide ${ }^{[8,16]}$. That is due to agriculture stressors and development ${ }^{[15]}$. Wetlands have been reduced by more than $50 \%$ globally [17, 18], with one-third to one-half changes in land surface involved human influences ${ }^{[19]}$. With the gradual wetlands due to development and pollution, these species deteriorating relationship with vegetation is consummate data to understand species diversity and vegetation before it is too late. The effects of urbanization on avian diversity may be mitigated by wetlands, enhancing habitat, and increasing resource availability. 
Nonetheless, one of the major driving forces in the destruction of natural wetlands is urbanization $[20,21]$ in wetland habitat quality. Avian is considered suitable biomarker ${ }^{[22]}$. They also considered surrogates for assessing the impact of habitat changes ${ }^{[23,24]}$. Avian is an indicator of environmental changes due to their sensitivity to ecological variables ${ }^{[25]}$. This particular ability credits them to build homes anywhere globally as long as the vegetation and climate are suitable for survival. The forests with complex composition and floristic richness have a high diversity of avian communities [26-29]. However, to understand avian community structures and their relationships with vegetation type variations, it is important to relate them to changed habitats ${ }^{[30]}$. Therefore, it is important to assess the relationship between avian and habitat changes ${ }^{[31-34]}$. Vegetation cover was positively related to avian species richness [35]. Avian has ranked as one of the critical components of vegetation dynamics, helping assess vegetation cover environmental effects more clearly ${ }^{[36]}$. This research is the first to be done in the study area, our objective was to find the relationship between vegetation cover in Tianfu national wetland park and bird communities, In keeping with this understanding, and we conceptualized the hypothesis. Does vegetation change affect the avian community in Tianfu National Wetland Park? Do avian abundance, richness, and diversity will vary seasonally?

\section{Material and Methods}

\subsection{Study area}

The study area is located in the Kunshan Tianfu National Wetland Park in Suzhou City, Jiangsu Province (East longitude $121^{\circ} 05^{\prime} 22.32^{\prime \prime}-121^{\circ} 07^{\prime} 44.08^{\prime \prime}$, North latitude $\left.31^{\circ} 19^{\prime} 18.28^{\prime \prime}-31^{\circ} 21^{\prime} 13.53^{\prime \prime}\right)$. The Park is located in the Huaqiao Economic Development Zone of Kunshan City, in the middle reaches of the Wusong River in the Taihu Lake Basin, $5 \mathrm{~km}$ from the Wusong River's mainstream, and the total approved area of the wetland park is $779.54 \mathrm{~km}^{2}$. (Fig.1). The Park is located in the northern subtropical southern monsoon climate zone. The historical extreme maximum temperature is $39.7^{\circ} \mathrm{C}$, and the historical extreme minimum temperature is $-11.7^{\circ} \mathrm{C}$. The annual frost-free period is 239 days; the average yearly temperature is $17.6^{\circ} \mathrm{C}$. With four distinct seasons, the climate is mild and humid with sufficient sunshine and abundant rainfall. The average yearly precipitation is $1200.4 \mathrm{~mm}$, and the annual average sunshine time is 1789.2 hours. The prevailing wind direction is the southeast wind throughout the year, and the secondary general wind direction is northwest wind [37]. As a result, the air quality is excellent, reaching the national secondary standard for more than 300 days a year, and it has a good living climate. 

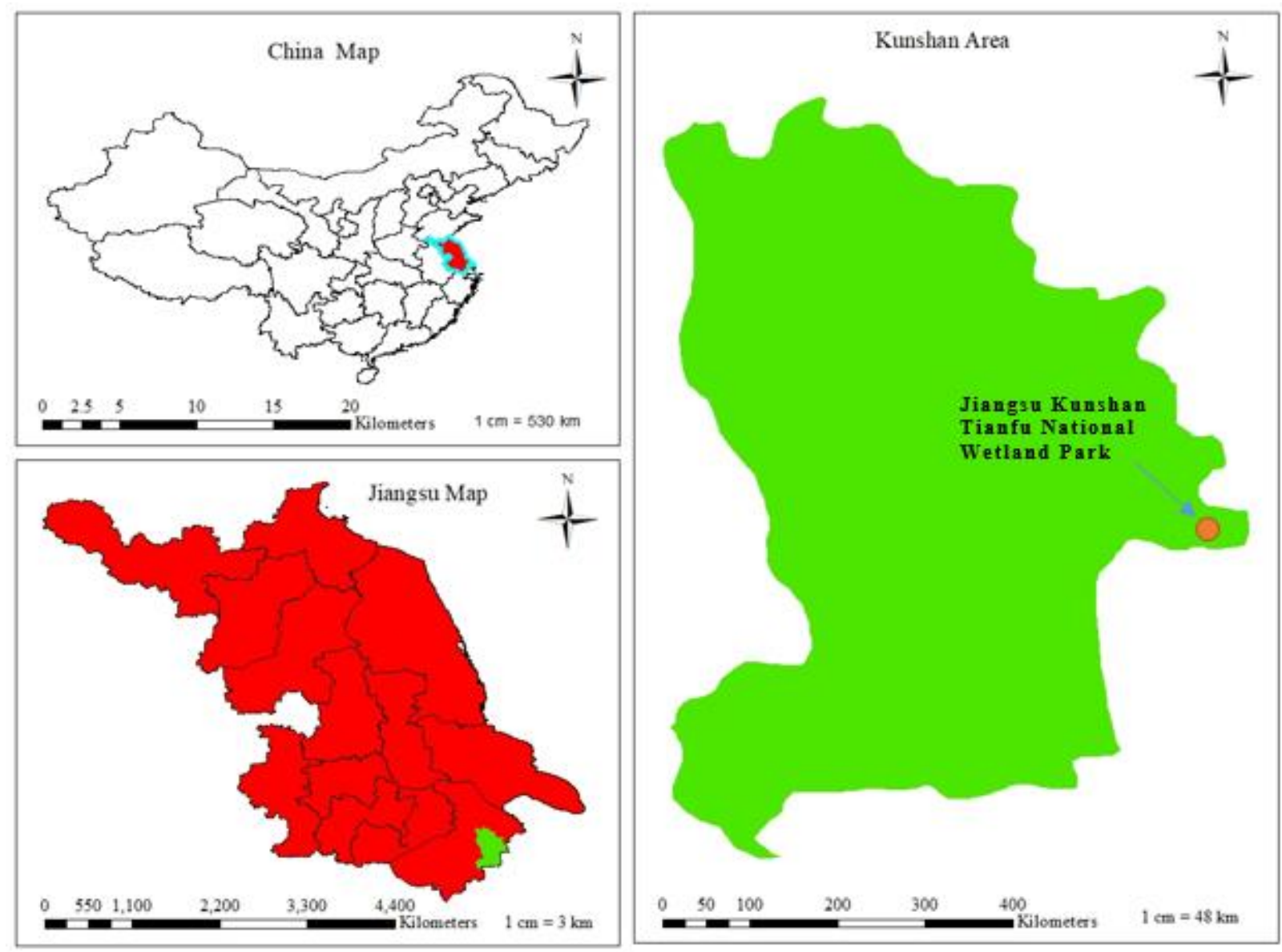

Figure 1: The map shows the study area location of the wetland park in Kunshan, Jiangsu, China.

The avian habitat restoration area was formerly known as horse racing track, so it is currently nicknamed 'horse farm'. A typical artificially restored wetland covers 700 acres and mainly uses farmland-pond-grassland as the primary habitat type. Since the renovation and restoration in 2017 (Fig. 2), it has been following low-impact management for natural vegetation succession. Internal meadows and open water provide a habitat for a variety of wild animals. The surrounding farmland guarantees food sources and complete ecosystem services, made the racecourse become a unique landscape of Tianfu National Wetland Park. ${ }^{[37]}$. 

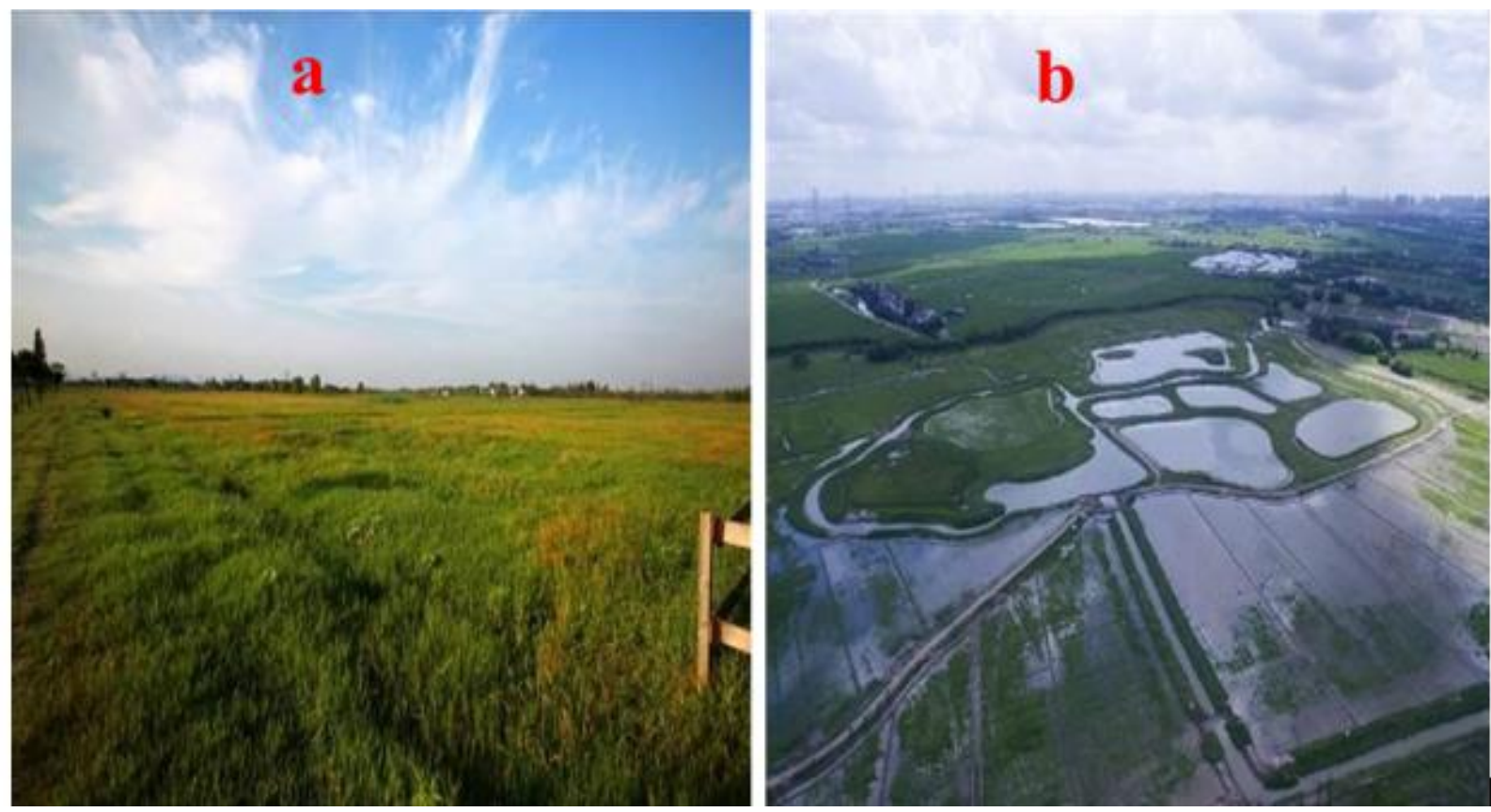

Figure 2: (a) Study site before restoration and (b). The site after restoration (Photos owned by Tianfu National Wetland Park)

\subsection{Vegetation field survey}

One hundred Forty-seven samples were investigated in Tianfu National Wetland Park (Fig. 3). In each trip to determine the vegetation cover-abundance using $1 * 1 \mathrm{~m}^{2}$ quadrate randomly and estimated present grass. All plants observed were calculated and classified into four seasons.

Data was recorded in detail of the types, quantity, and coverage. In addition, photos were taken. For the Species identification: refer to 《Flora of China》, 《Flora of Jiangsu》, 《East China Seed Plant Retrieval Manual》, 《Shanghai Vascular Key Plant》 and 《300 Species of Wild Flowers in East China》. Quantity and coverage were estimated by visual observation; $1 \mathrm{~m} \times 1 \mathrm{~m}$ quadrate plot sampling was used, three plants of each species were selected in good condition, dugout, put into sample bags, and taken back to the laboratory for identification and classification. Vegetation survey has been done in summer and autumn of 2019 and winter and spring of 2020. 


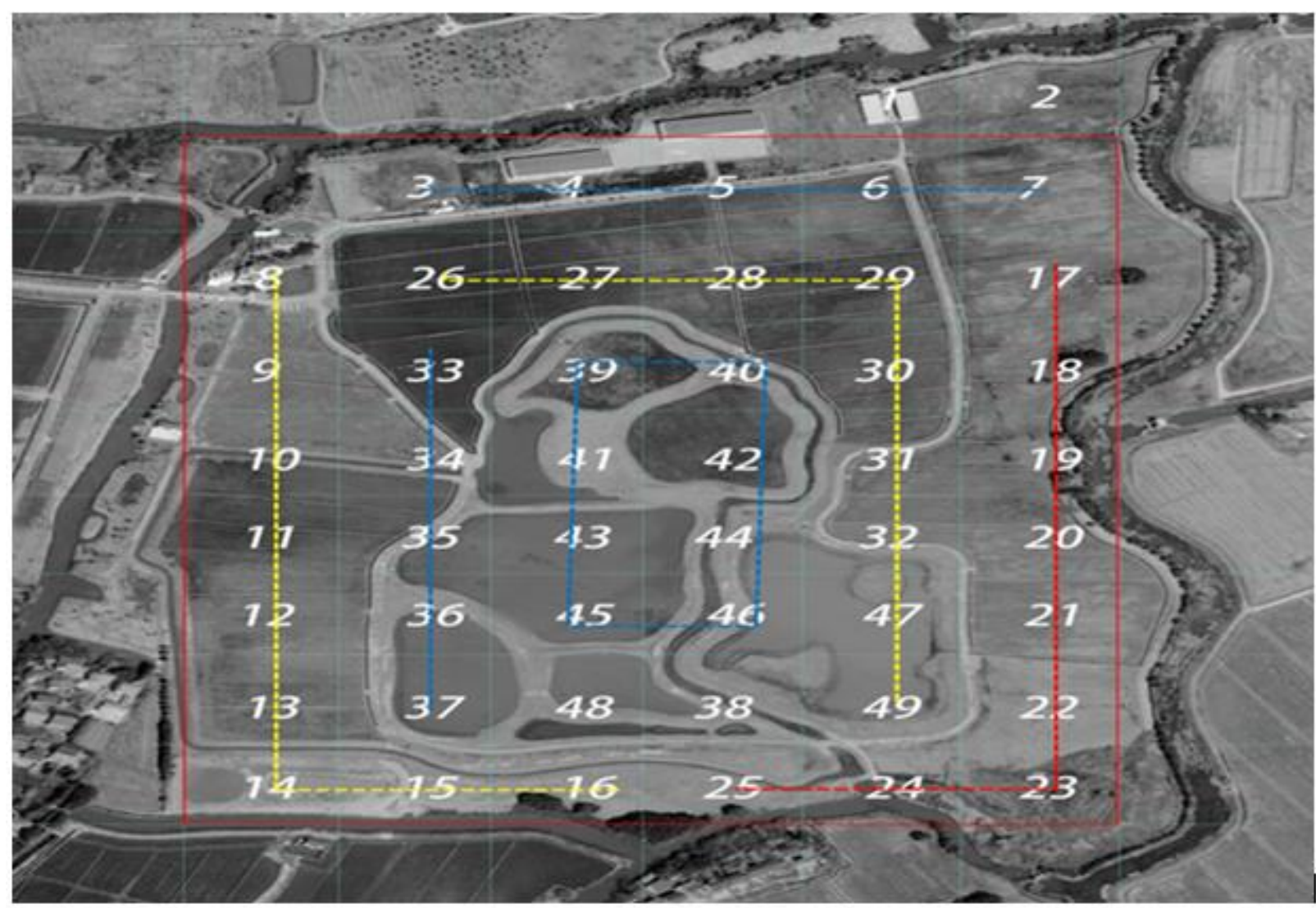

Figure 3: Plants Sample plots in Tianfu National Wetland Park. Samples are outlined with numbers to show the sequencing.

\subsection{Avian field survey}

Avian was observed in the study site along with five plots; we used the distance sampling method ${ }^{[38]}$ To collect information on avian species abundances and identified during summer and autumn of 2019 and winter and spring of 2020 . During the field surveys, avian were identified in the morning from 7:00 AM to 10:00 AM and afternoon from 3:00 PM to 6.30 PM, when the temperature was relatively calm, and the avian's activities were high ${ }^{[38]}$. On every side, all avian seen were recorded or heard during the 15 minutes. In the first five minutes, the survey will wait until avian species settled due to arrival disturbances. The remaining ten minutes record all species observed or heard on every occasion; only avian that land in the sites were recorded ${ }^{[39]}$

\subsection{Statistical Analysis}

The data was prepared using Microsoft Excel to determine the plant abundance in the seasons, and we added all individual plants of the month in the season. We obtained species richness (S) by counting the number of species 
present. To get genera and family richness, we added the number of genera and families in each season.

BioDiversity Pro was used to compute Shannon-Wiener diversity ( $\left.\mathrm{H}^{\prime}\right)$, Shannon evenness $\left(\mathrm{J}^{\prime}\right)$, and Simpson's index of dominance (D'). Shannon Wiener's diversity index combines species richness and evenness. It provides heterogeneity information for ecological studies ${ }^{[75-77]}$ about plants and avian. ANOVA was used to determine the variations among different seasons, and correlation analysis was used to establish associations between vegetation cover and avian diversity measures between summer and autumn 2019 using SPSS (version 25). GraphPad Prism (version 8.1) was used for graphing to determine the variations among different seasons.

\section{Results}

\subsubsection{Vegetation cover-abundance and richness}

No significant difference in the vegetation cover, total species and richness was observed in the ANOVA test among seasons $\left[F_{3,588}=0.889, p=0.45\right]$. The highest vegetation cover richness was noted in summer ( 75 Species), followed by autumn and spring, which accounted for 71, 66 species. The lowest vegetation cover richness observed (48 species) was obtained in winter 2020. While the vegetation cover total individuals showed the highest value in the autumn (45066 plants) followed by winter (38281 plants) and summer (34490 plants). The lowest abundance value was recorded in spring (18235 plants) (Table1 and Fig. 4a). Vegetation richness was reported highest in summer (Fig. 4b) which belongs to 46 genera and 24 families. Autumn recorded second highest vegetation richness with 49 genera and 35 families (Fig. 4c).

Table 1: Vegetation cover-abundance richness and diversity indices in the Tianfu National Wetland Park.

\begin{tabular}{lllll}
\hline & \multicolumn{2}{c}{2019} & \multicolumn{2}{c}{2020} \\
\cline { 2 - 5 } Measures & Summer & Autumn & Winter & Spring \\
Total Individuals & 34490 & 45066 & 38281 & 18235 \\
Total Species & 75 & 71 & 48 & 66 \\
Shannon H' & 1.088 & 1.195 & 1.062 & 1.153 \\
Shannon J' & 0.58 & 0.646 & 0.632 & 0.634 \\
Simpsons Diversity (D) & 0.15 & 0.1 & 0.126 & 0.144 \\
\hline
\end{tabular}



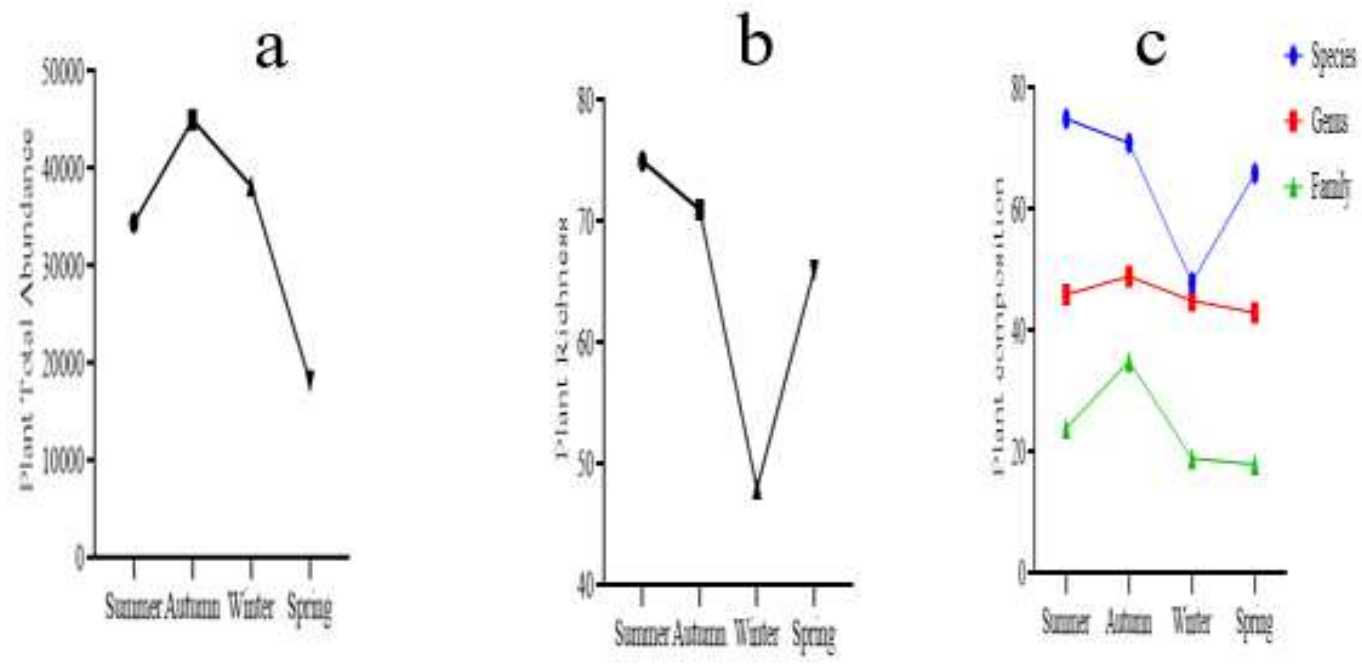

Figure 4: Vegetation cover (i.e. total abundance), species richness fluctuation and composition among the seasons.

Vegetation cover abundance and species evaluation showed five highest species abundance at the park. Meanwhile, only Cynodon dactylon was abundantly common all through the seasons (Fig. 5). The other species may influence avian abundance and diversity more than the plant in common. Therefore, it can be concluded that a specific plant can support certain avian species. For all seasons, summer has the highest plant richness while spring was the lowest. 


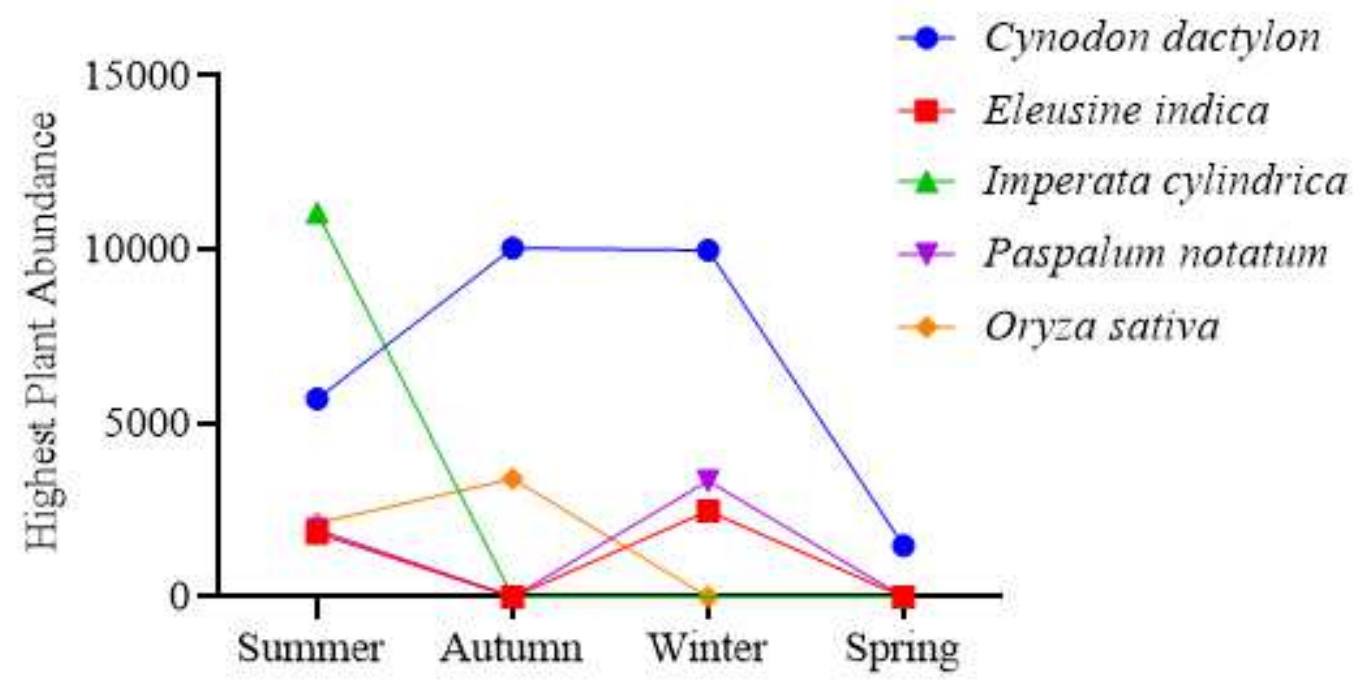

Figure 5: Most frequently observed plant species in the Tianfu National Wetland Park.

\subsubsection{Avian abundance and richness}

A significant difference in the avian's richness was observed in the ANOVA test among seasons $\left[\mathrm{F}_{3,147}=4.600, \mathrm{p}=0.18\right]$, the highest avian abundance richness was noted in the winter (1292) and spring (1255), while the autumn and summer has the lowest. Avian total species in spring 2020 recorded the highest number as 76 species followed by autumn, 62 species. The lowest avian richness was obtained in summer, 43 species (Table 2). In comparison among seasons, avian species richness was higher in spring and winter (Fig. 6a). Meanwhile, the total individual showed higher values in spring and autumn than in summer and winter (Fig. 6b). This avian richness belonged to 24, 33 genera, and 8, 12 families in summer and autumn, respectively (Fig. 6c). 
Table 2: Avian abundance, richness and diversity indices in the Tianfu National Wetland Park.

\begin{tabular}{lllll}
\hline & \multicolumn{2}{c}{2019} & \multicolumn{2}{c}{2020} \\
\hline Measures & Summer & Autumn & Winter & Spring \\
\cline { 2 - 5 } Total Individuals & 276 & 974 & 1255 & 1292 \\
Total Species & 43 & 62 & 60 & 76 \\
Shannon H' Log Base 10. & 1.448 & 1.498 & 1.359 & 1.495 \\
Shannon J' & 0.886 & 0.836 & 0.764 & 0.795 \\
Simpsons Diversity (D) & 0.045 & 0.044 & 0.08 & 0.047 \\
\hline
\end{tabular}
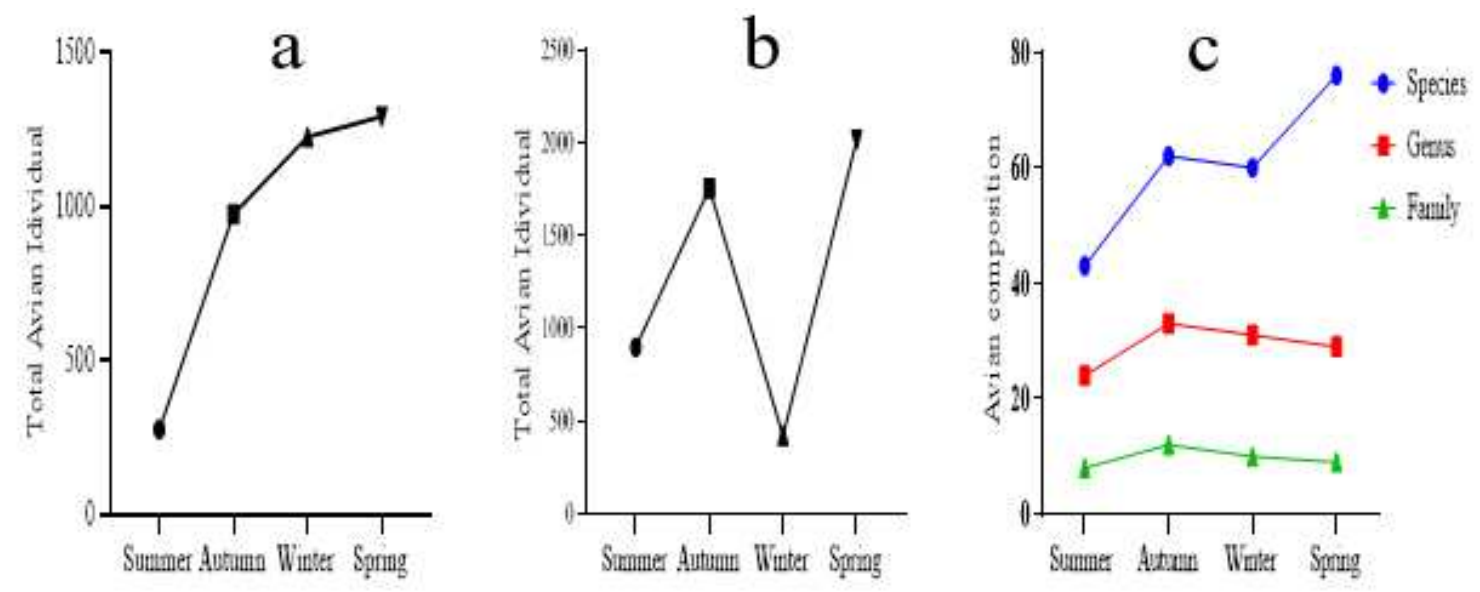

Figure 6: Avian richness, individuals (i.e. total abundance), and composition among the seasons

\subsubsection{Diversity of vegetation}

Shannon wiener diversity $\left(\mathrm{H}^{\prime}\right)$ and Shannon Evenness $\left(\mathrm{J}^{\prime}\right)$ showed higher values in autumn $\left(\mathrm{H}^{\prime}=1.195\right)$ and $\left(\mathrm{J}^{\prime}=0.646\right)$, respectively, whereas the higher Simpson index values were in summer $(D=0.15)$ followed by spring and winter. It can be noted that avian $\left(\mathrm{H}^{\prime}\right)$ value was higher in spring (1.582). Similarly, Shannon Evenness $\left(\mathrm{J}^{\prime}\right)$ values showed higher distribution in spring $\left(\mathrm{J}^{\prime}=0.891\right)$ (Fig. 7). Simpson diversity index was not significantly different among the seasons with a little high values in summer $(\mathrm{D}=0.08)$. Therefore, our results deduce that the plant diversity $\left(\mathrm{H}^{\prime}\right)$ and evenness $\left(\mathrm{J}^{\prime}\right)$ in Tianfu national wetland park have low diversity measures in all seasons. The vegetation has low species diversity, but the community individuals are not distributed equitably among these species. Simpson 
diversity showed a slight difference between seasons, whereas avian diversity showed a significant variation $(\mathrm{p}<0.05)$.

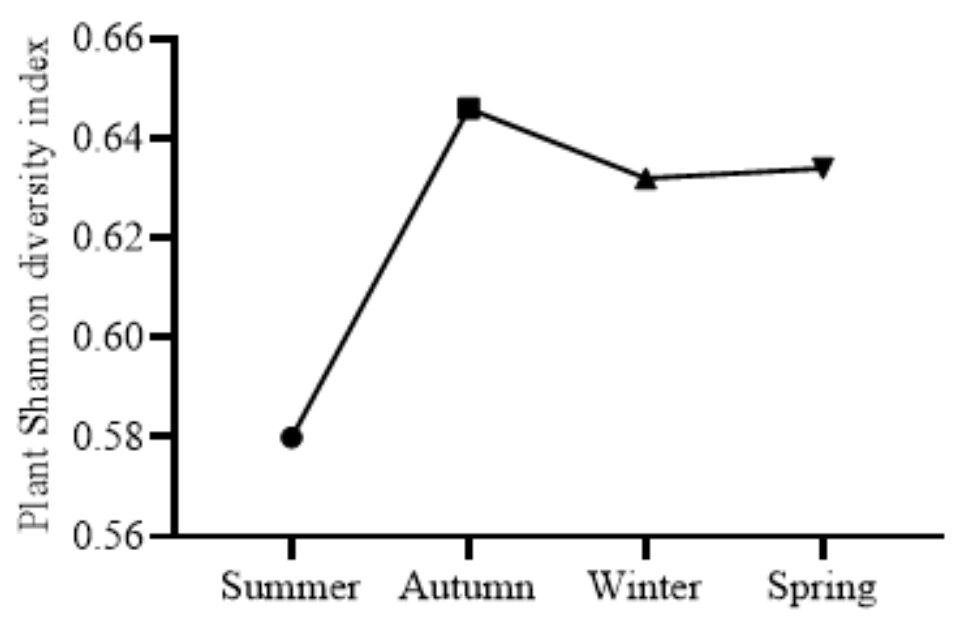

Figure 7: Plant Shannon diversity among seasons

\subsubsection{Vegetation cover and avian relationship}

At the species level in autumn, plant and avian were positively correlated ( $p$ $<0.05)$ while at the genus level, the number of plants observed in the summer was positively correlated with the number of avian $(\mathrm{p}<0.05)$. The number of avian genera in autumn was associated positively with autumn plants $(\mathrm{p}<0.05)$, Fig. 8 .

It can be concluded that plants were in a good relationship with the avian in different seasons, and we assume that varying levels of disturbance might have had other effects on diversity. We suggest careful conceptualization, where our goal is to preserve biodiversity in a given area. In that case, we need to understand how different management strategies impact diversity because diversity indices can provide more information than merely the number of species present. 

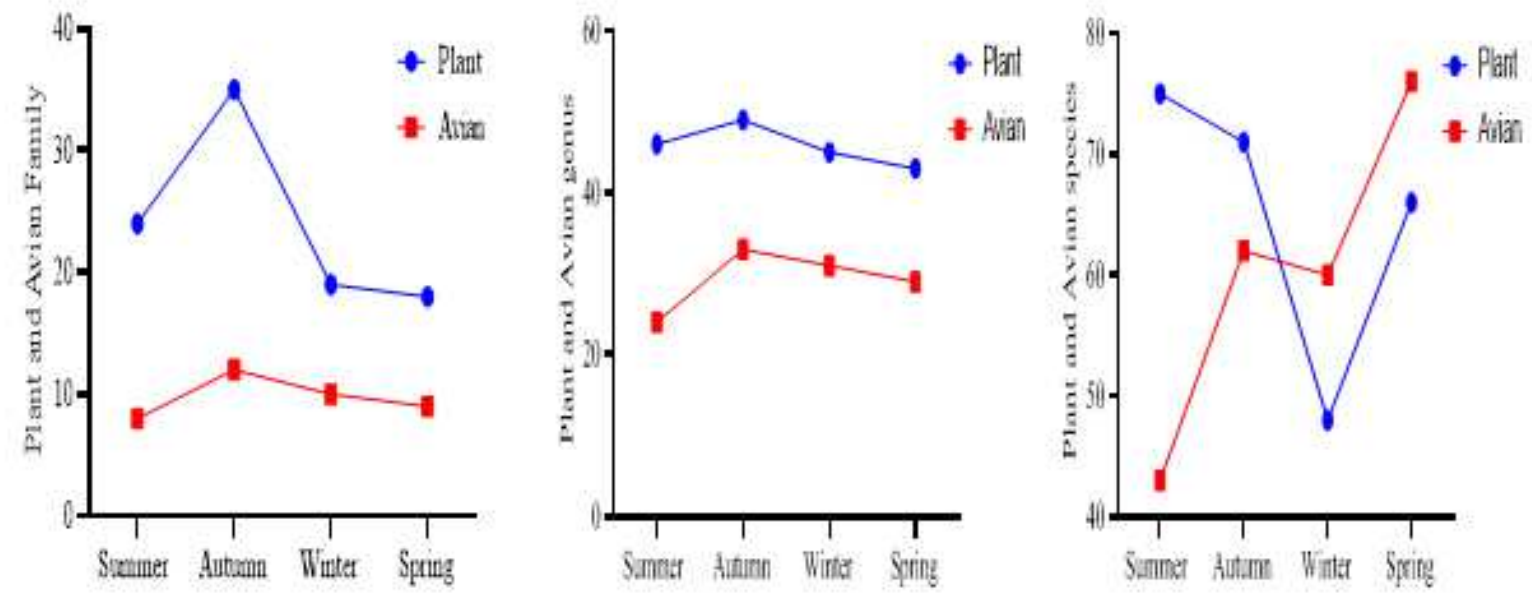

Figure 8: Plant and Avian relationship at Family, Genus, and Species level.

\section{Discussion}

The relationships between avian communities and vegetation composition have been established mainly at the wetland ${ }^{[40-42] . ~ T h e ~ s c i e n t i f i c ~ r e s e a r c h ~ s h o w e d ~}$ that the species composition changes could influence habitat selection and the avian community structure ${ }^{[40,43,44]}$. The avian abundance and species composition increased with an increase in vegetation cover. Meanwhile, our results fit our hypothesis that the number of avian and avian species richness would increase linearly with increased vegetation cover. Similarly, ${ }^{[45]}$ concluded that the amount of vegetation cover was the most important variable determining avian species richness. Also, ${ }^{[46]}$ indicates that the avian species abundance was associated with habitat variation.

In our research and those of others ${ }^{[42]}$ correlation between plants diversity indices (Shannon, Simpson) and avian species richness was confirmed. Also, the correlation between plants and avian species richness was established, similarly to our findings that grasslands support a significant number of avian species which is consistent with other studies elsewhere in the tropics ${ }^{[19,32-34]}$. Plant communities and avian communities varied depending on the environmental transformation. These results showed that species composition is associated with floristic diversity $[42,45,46]$. A strong correlation between avian community and habitat diversity indices suggests that avian is dependent on the compositional complexity of trees, shrubs, and herbs. These observations indicate that an avian community is significantly associated with plant species diversity [34, 47, 48]. Avian diversity increased along a gradient of growing vegetation complexity in shrub-steppe habitats, primarily through new avian species or even entire guilds [49, 50]. 
However, our results confirm that vegetation structure explains well avian species diversity and the floristic composition of the tree layer expressed as species richness and diversity were poor predictors of avian species richness and diversity [51-53]. Nevertheless, the abundance of some specific tree species or group of tree species may explain the distributions of particular avian species or avian guilds [54, 55]. An important factor affecting the number of avian is the degree of transformation of grassy and shrubby layers for ground avian [56].

Consistent with our second prediction, the number of species, families, and genera was varied in all seasons; some authors suggested that the transformed environment could reduce species abundance because of a decrease in some species' populations. Limited and rare species were eliminated from many regions [57]. Loss of rare and limited species can lead to the degradation of ecosystem functions ${ }^{[58]}$.

Also, our results show that avian species' abundance and diversity were different between seasons, suggesting that other factors might influence these community properties. This relationship is possibly linked to seasonal differences in the environment, annual precipitation patterns (which affect avian community composition) and also the amount of food supplied by different shrub and tree species, which differ in their flowering and fruiting patterns ${ }^{[59]}$. In the study conducted in urban environments, avian species richness was related to the number of trees, which may further affect avian diversity as avian move into urban centers ${ }^{[63]}$. Previous studies have found that forests with greater structural complexity and many plant species are richer in avian communities. Meanwhile, Tu et al., [67] showed that grasslands (such as sub-types, tall grasslands, tall marshes, and bamboo grasslands) increased avian species richness and evenness positively. 


\section{Conclusion}

There are increasing efforts to promote the conservation of biodiversity on farmland, minimizing impacts on economic output and enhancing landscape heterogeneity. Our study shows no statistically significant difference in vegetation cover observed and vegetation richness during the seasons, which may be due to the study area size. However, avian were statistically varied, and it can be assumed that this variation is due to seasonal migration. Diversity measures showed a very strong relationship between vegetation cover and avian in summer. Though vegetation analysis alone cannot juxtapose the avian-plant interaction, evaluation of the other influencing factors, such as plant maturity, water quality, etc., would be needed for future research in the area. Our work has provided an essential and much-needed baseline for management and conservation issues related to vegetation cover and avian diversity in the area. Also, we call for more surveys to be done to investigate avian food behaviors and minimize farmland intensification in the area. 


\section{References}

1. Hostetler, M. and K. Knowles-Yanez, Land use, scale, and bird distributions 2003.

2. Farmer, M.C., M.C. Wallace, and M. Shiroya, Bird diversity indicates ecological value in urban home prices. Urban Ecosystems, 2011. 16(1): p. 131-144.

3. Willig, M.R., D.M. Kaufman, and R.D. Stevens, Latitudinal Gradients of Biodiversity: Pattern, Process, Scale, and Synthesis. Annual Review of Ecology, Evolution, and Systematics, 2003. 34(1): p. 273-309.

4. Guadagnin, D.L., et al., Spatial and Temporal Patterns of Waterbird Assemblages 2005.

5. Cintra, R., P.M.R.S.D. Santos, and C.B. Leite, Composition and Structure of the Lacustrine Bird Communities. 2013.

6. BEERLING, D.J., et al., Testing the responses of dynamic global vegetation. 1997.

7. Mata-González, R., et al., Invasive plants and plant diversity as affected by groundwater depth and microtopography in the Great Basin. Ecohydrology, 2012. 5(5): p. 648-655.

8. ANDREW, S., M., et al., Growth Performance of Azadirachta Indica Provinances in Morogoro, Tanzania. 2004.

9. $\quad$ Rotenberry, J.T., The role of habitat in avian community composition. 1985.

10. Nally, R.C.M., The roles of floristics and physiognomy in avian community composition. 1990.

11. George, T.L. and D.S. Dobkin, Effects of Habitat Fragmentation on Birds in Western Landscapes Contrast With Paradigms from the Eastern United States 2002.

12. Radford, J.Q. and A.F. Bennett, The relative importance of landscape properties for woodland birds in agricultural environments. Journal of Applied Ecology, 2007. 44(4): p. 737-747.

13. Kennedy, C.M., et al., Landscape matrix and species traits mediate responses of Neotropical. 2010.

14. ZEDLER, J.B. and S. Kercher, Wetland Resources Status, Trends, Ecosystem Services, and Restorability. Annual Review of Environment and Resources, 2005. 30(1): p. 39-74.

15. Ntongani, W.A. and S.M. Andrew, Bird species composition and diversity in habitats with different disturbance histories at Kilombero Wetland, Tanzania. Open Journal of Ecology, 2013. 03(07): p. 482-488.

16. Juliard, R., F.J. Iguet, and D. Couvet, common birds facing global change:what makes the special at risk. 2003.

17. Mitsch, W.J. and J.W. Day, Restoration of wetlands in the Mississippi-Ohio-Missouri (MOM) River Basin: Experience and needed research. Ecological Engineering, 2006. 26(1): p. 55-69.

18. Rajpar, M.N. and M. Zakaria, Bird Species Abundance and Their Correlations with Microclimate and Habitat Variables at Natural Wetland Reserve, Peninsular Malaysia. International Journal of Zoology, 2011. 2011: p. 1-17.

19. Tyrväinen, L., H. Silvennoinen, and O. Kolehmainen, Ecological and aesthetic values in urban forest management. Urban Forestry \& Urban Greening, 2003. 1: p. 135-149.

20. Russi D, et al., The economics of ecosystems and biodiversity for water and wetlands 2013.

21. Luo, K., et al., Bird diversity and waterbird habitat preferences in relation to wetland restoration at Dianchi Lake, south-west China. Avian Research, 2019. 10(1).

22. Seymour, C.L. and R.E. Simmons, Can severely fragmented patches of riparian vegetation still be important for arid-land bird diversity? Journal of Arid Environments, 2008. 72(12): p. 2275-2281. 
23. Veraart, J.A., et al., Selection of (bio) indicators to assess effects of freshwater use in wetlands: a case study of Albufera de Mallorca, Spain. Regional Environmental Change, 2004. 4(2-3): p. 107-117.

24. Ma, Z., et al., Waterbird population changes in the wetlands at Chongming Dongtan in the Yangtze River estuary, China. Environ Manage, 2009. 43(6): p. 1187-200.

25. Cotgreave, P. and P.H. Harvey, Evenness of abundance in bird communities. 1994.

26. Easton, W.E. and K. Martin, Effects of Thinning and Herbicide Treatments on Nest-site Selection by Songbirds in Young Managed Forests. 2002.

27. Westphal, M.I., et al., Effects of landscape pattern on bird species distribution in the Mt. Lofty. 2002.

28. Wilson, M.W., et al., Effects of growth stage and tree species composition on breeding bird assemblages of plantation forests. Bird Study, 2010. 53(3): p. 225-236.

29. Gibbs, S., et al., Avian diversity in a temperate tree-based intercropping system from inception to now. Agroforestry Systems, 2016. 90(5): p. 905-916.

30. Wiens, J.A. and J.T. Rotenberry, Censusing and the Evaluation of Avian Habitat Occupancy 1981.

31. CANTERBURY, G.E., et al., Bird Communities and Habitat as Ecological Indicators of Forest Condition in Regional Monitoring. Conservation Biology, 2000. 14(2): p. 544-558.

32. Lindenmayer, D.B., C.R. Margules, and D.B. Botkin, Indicators of Biodiversity for Ecologically Sustainable Forest Management. Conservation Biology, 2000. 14(4): p. 941950.

33. O'Connell, T.J., L.E. Jackson, and R.P. Brooks, Bird Guilds as Indicators of Ecological Condition in the Central Applachiance. Ecological Applications, 2000. 10(6): p. 17061721.

34. CHETTRI, N., et al., The Relationship Between Bird Communities and Habitat. Mountain Research and Development, 2005. 25(3): p. 235-243.

35. Villegas, M. and Á. Garitano-Zavala, Bird community responses to different urban conditions in La Paz, Bolivia. Urban Ecosystems, 2010. 13(3): p. 375-391.

36. Peng, J., et al., Vegetation coverage change and associated driving forces in mountain areas of Northwestern Yunnan, China using RS and GIS. Environ Monit Assess, 2012. 184(8): p. 4787-98.

37. $\quad$ T.N.W.P, Tianfu National Wetland Park Bird Investigation Report (2018) 2018.

38. J.Bibby, C., et al., Bird Census Techniques Extract.

39. O'Reilly, L., et al., Effects of fire on bird diversity and abundance in an East African savanna. 2006.

40. Erdelen, M., Bird communities and vegetation structure: I. Correlations and comparisons of simple and diversity indices. Oecologia, 1984. 61(2): p. 277-284.

41. Sara Sanchez, José Javier Cuervo, and E. Moreno, Vegetation Structure in Beech-Fir Forests Effects on the Avian Community. 2012.

42. BLINKOVA, O. and T. Shupova, Bird Communities and Vegetation Composition in the Urban Forest Ecosystem: Correlations and Comparisons of Diversity Indices. Ekológia (Bratislava), 2017. 36(4): p. 366-387.

43. AARON P. GABBE, SCOTTK RBINSON, and J.D. BRAWN, Tree-Species Preferences of Foraging Insectivorous Birds : implications for Floodplain Forest Restoration. Conservation Biology, 2001.

44. Rodewaled, A.D. and M.D. Abrams, Floristics and Avian Community Structure. 2001. 
45. Roth, R.R., Spatial Heterogeneity and Bird Species Diversity. Ecology, 1976. 57(4): p. 773-782.

46. Lewis, K.P. and B.M. Starzomski, Bird communities and vegetation associations across a treeline ecotone in the Mealy Mountains, Labrador, which is an understudied part of the boreal forest. Canadian Journal of Zoology, 2015. 93(6): p. 477-486.

47. Winterntz, B.L., Temporal Change and Habitat Preference of Some Montane Breeding Birds 1976.

48. James, F.C. and N.O. Wamer, Relationships between Temperate Forest Bird Communities and Vegetation Structure. Ecology, 1982. 63(1): p. 159-171.

49. Wiens, J.A. and J.T. Rotenberry, Habitat Associations and Community Structure of Birds in Shrubsteppe Environments. Ecological Monographs, 1981. 51(1): p. 21-42.

50. Fares Khoury, et al., The effect of vegetation cover on bird communities in a hyperarid desert. Zoology in the Middle East, 2014.

51. MacArthur, R.H. and J.W. MacArthur, On Bird Species Diversity. Ecology, 1961. 42(3): p. 594-598.

52. Karr, J.R., Structure of Avian Communities in Selected Panama and Illinois Habitats. Ecological Monographs, 1971. 41(3): p. 207-233.

53. Thinh, V., Bird species richness and diversity in relation to vegetation in Bavi National Park, Vietnam. Ornithological Science, 2006. 5: p. 121-125.

54. Rice, J., R.D. Ohmart, and B.W. Anderson, Habitat Selection Attributes of an Avian Community: A Discriminant Analysis Investigation. Ecological Monographs, 1983. 53(3): p. 263-290.

55. Douglas, D.C., et al., Avian Habitat Associations in Riparian Zones of Idaho's Centennial Mountains. The Wilson Bulletin, 1992. 104(3): p. 485-500.

56. Blinkova, O. and T. Shupova, Bird Communities and Vegetation Composition in the Urban Forest Ecosystem: Correlations and Comparisons of Diversity Indices. Ekológia (Bratislava), 2017. 36.

57. Kornan, M., M. Svitok, and A. Kristin, Null model analyses of temporal patterns of bird assemblages and their foraging guilds revealed the predominance of positive and random associations. Ecol Evol, 2019. 9(15): p. 8541-8554.

58. Seymour, C.L., et al., On Bird Functional Diversity: Species Richness and Functional Differentiation Show Contrasting Responses to Rainfall and Vegetation Structure in an Arid Landscape. Ecosystems, 2015. 18(6): p. 971-984.

59. CORRAL, A., et al., Plant-bird mutualistic interactions can contribute to the regeneration of forest and non-forest urban patches in the Brazilian Cerrado. Urban Ecosystems, 2020. 24(1): p. 205-213. 


\section{Supplementary Files}

This is a list of supplementary files associated with this preprint. Click to download.

- SupplementaryMaterials.docx 